\title{
PODE MESMO FILMAR (MOSTRAR) ISSO? O ACASO COMO FORÇA DE CINEMA NA ESCOLA*
}

\author{
Eduardo de Oliveira Belleza \\ Wenceslao Machado de Oliveira Jr
}

\begin{abstract}
Resumo
Quais tipos de situações podem surgir quando uma câmera passa a compor com o universo escolar? O presente texto busca expressar um mapa dos acasos emergidos do encontro entre cinema e escola, quando o corpo humano é acoplado a uma câmera num ambiente escolar. Este mapa será traçado a partir de duas linhas de intensidade: a linha dos jovens e a linha das crianças pequenas, cada uma vivenciada em uma pesquisa: "O documentário e a escuta sensível do lugar: quando escola e cinema formam um povo" e "Lugar-escola e cinema: afetos e metamorfoses mútuas: do espaço às filmagens - das filmagens ao espaço". Elas atravessam percursos diferentes nas relações entre cinema e escola, onde diversos usos do acaso atuaram como força da produção de filmes e de formas de vida humanas e inumanas. O compartilhamento de alguns operadores políticos e conceituais levam ambas pesquisas a apostar na escola como lugar de negociações criadoras de outros (mundos) possíveis e nas imagens do cinema como potência para colocar boas questões ao pensamento, tendo no acaso (dos encontros) uma das forças que mais nos levaram a experimentar negociações e pensamentos imprevistos e, justo por isto, potentes para tornar sensíveis outras (formas de) vidas.
\end{abstract}

\section{Introdução}

"Professora, posso filmar sua aula?" A fala do estudante revela uma situação cada vez mais comum na educação escolar: a presença de câmeras conectadas a diversas redes sociais. Isto tem colocado um desafio às/aos educadores/as de um modo geral: ao invés de criar um interdito, inventar maneiras de como compor com a produção de imagens na escola. Acreditamos que tal desafio é da ordem das invenções possíveis que nosso estar professor/a congrega para si. Ou seja, experimentar cada vez mais com as câmeras e com os desejos em curso parece um movimento interessante para produzirmos, juntos com as/os estudantes, outros percursos educativos.

Acontece que, quase sempre, a presença de celulares e os riscos que apresentam a partir de situações que incomodam (a produção de imagens, por exemplo), criam, no mínimo, receios e medos que têm gerado tensões, ampliadas pelos movimentos recentes de restrição à liberdade de ensino fortemente apoiados em gravações de sons e imagens em situações escolares ${ }^{1}$. Muitas vezes estas gravações são realizadas sem permissão, ou seja, sem que a pergunta que inicia o parágrafo anterior tenha sido feita.

\footnotetext{
* DOI - 10.29388/978-65-86678-51-2-0-f.389-404

${ }^{1} \mathrm{O}$ mais conhecido destes movimentos é o Escola sem Partido. https://www.escolasempartido.org/
} 
Ao mesmo tempo que as tensões e desconfianças entre escolas e celulares se ampliam, acreditamos ser possível, para não dizer necessário, estabelecer uma situação de muito proveito quando, diante de tais riscos e medos, nos vemos forçados a inventar outras formas de aprender, outras formas de experimentar o mundo e apontar a importância atual das imagens audiovisuais e suas ferramentas de produção.

Este texto reúne algumas experimentações em torno desta situação de aprendizado e invenções audiovisuais efetivadas em duas pesquisas: "O documentário e a escuta sensivel do lugar: quando escola e cinema formam um povo" (BELLEZA, 2019) e "Lugar-escola e cinema: afetos e metamorfoses mútuas: do espaço às filmagens - das filmagens ao espaço" ". Ambas são tributárias do Programa Cinema e educação: a experiência do cinema na escola de educação básica ${ }^{4}$, da Prefeitura Municipal de Campinas, e congregam algumas coisas em comum: 1. a escola como um lugar, como "ponto de encontro", como uma constelação de processos, 2. o cinema como um gesto no mundo capaz de criar outras formas de ver e sentir e 3. as pessoas - crianças, jovens e professoras/es munidos de câmera perambulando pela escola com nenhuma ou algumas ideias na cabeça. Este texto, portanto, funciona como um mapa dos acasos, entendidos como encontros alegres ${ }^{5}$ que nos fizeram desviar o rumo em algum momento e parar, reparar e encontrar algo que valia a pena filmar, mostrar e (d)escrever.

Foi possível observar dois tipos de encontros alegres distintos: encontros no lugar e encontros na imagem. Encontros no lugar foram aqueles que levaram as pessoas a filmar algo devido a alguma "potência espacial" (OLIVEIRA JR, 2016) que as atravessou ali, naquele lugar-escola; já encontros na imagem entendemos como sendo aqueles onde a potência esteve relacionada ao contato com uma filmagem já realizada, naquilo que ela despertou enquanto sensação-pensamento.

Ambos são encontros criativos, porém, são processos de produção que diferem, e, para nossa análise, significam um olhar específico. De um lado observamos quais potências espaciais foram impulso para filmar algo; de outro lado, o impulso é a partir de uma imagem já constituída, mas que ainda reverbera por fazer pensar algo que não poderia ser pensado antes dela. Juntos, esses encontros nos revelam as potências da relação cinema e

\footnotetext{
${ }^{2}$ Esta pesquisa foi realizada na Escola Municipal de Ensino Fundamental Elza Pellegrini, em Campinas-SP, e é tributário da pesquisa de doutorado homônima, financiada pela CAPES e defendida em 2019, no Programa de Pós-Graduação em Educação da Unicamp.

${ }^{3}$ Esta pesquisa está em andamento, tem financiamento da FAPESP (Processo 2018/09258-4) e está sendo realizada em dois Centros Municipais de Educação Infantil, CEI Regente Feijó e CEI Cha Il Sun, em Campinas-SP, os quais funcionam efetivamente como uma única escola, numa mesma quadra e com uma única equipe gestora.

${ }_{4}$ Programa da Secretaria Municipal de Educação que incentiva a criação de cineclubes nas escolas. Ele vem sendo realizado em parceria com o Museu da Imagem e do Som-MIS-Campinas e com o Laboratório de Estudos AudiovisuaisOLHO, da Faculdade de Educação/Unicamp. Disponível em:

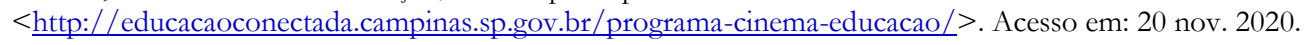

5 Trazemos aqui, de maneira muito resumida, o que entendemos como "encontro alegre", com o intuito apenas de fazer o leitor entender porque escolhemos tomar esta expressão para destacarmos os acasos como "potências de afetação afirmativa" num trabalho com o cinema (a arte) e assim nos aproximarmos da filosofia de Espinosa e da leitura que dele faz Deleuze. Grosso modo, Espinosa entende que somos afetados pelos corpos e ideias que nos chegam do mundo e que eles e elas geram afecções em nós, às quais ele distingue em dois grandes grupos: as paixões tristes e as paixões alegres. Para ele, "a tristeza diminui ou reduz a capacidade de agir do homem [... enquanto] a alegria aumenta ou favorece a capacidade de agir do homem” (ESPINOSA, 1992, p. 304-5). Na interpretação que Deleuze (2002) faz deste filósofo podemos ler que "sentimos alegria quando um corpo se encontra com o nosso e com ele se compõe, quando uma ideia se encontra com nossa alma e com ela se compõe; inversamente, sentimos tristęa quando um corpo ou uma ideia ameaçam nossa própria coerência" (DELEUZE, 2002, p. 25) e há a "diminuição da potência de agir ou do poder de ser afetado" (idem, p. 46). Neste sentido, um encontro alegre é aquele em que um corpo ou uma ideia ao encontrar-se com o nosso corpo aumenta nossa potência de agir e nosso poder de ser afetado pelo mundo na medida mesma que compõe conosco. Mais à frente no texto diremos que, durante as experimentações com cinema na escola, nosso corpo já será um corpo híbrido, composto com outro corpo que nos ampliou a potência de agir e de ser afetado: um corpo-câmera.
} 
escola, a qual nos parece ser atravessada pela força dos acasos ${ }^{6}$, o que nos leva a pensá-la, neste texto, a partir desta chave conceitual.

\section{Lugar e suas potências de acaso}

Antes de mais nada, permita-nos conceituar melhor o que estamos chamando de lugar e de potências espaciais. Para isso, o exercício aqui é o de tentar perceber a escola à luz de um conceito que temos usado no campo da geografia mais atual, o "[...] lugar como uma eventualidade” (MASSEY, 2008). Para a geógrafa Doreen Massey, o lugar é um acontecimento, ou melhor dizendo, uma eventualidade. Não é um recorte espacial paralisado do qual pudéssemos dizer: "olha só, é aquele o lugar." Muito pelo contrário, para esta geógrafa um lugar deve ser pensado como um cruzamento de trajetórias humanas e inumanas que incessantemente $\mathrm{e}^{7}$ se atravessam e se conectam, como uma constelação de processos em andamento perpétuo. Assim, ao invés de dizermos "olhe, chegamos no lugar" diríamos: "quais acontecimentos se dão aqui? De quais maneiras posso compor com as trajetórias aqui presentes?".

Na perspectiva de Doreen Massey (2008), o conceito de lugar está associado à esta copresença de uma constelação específica de trajetórias, fazendo com que um lugar seja estabelecido pelas interconexões e desconexões entre elas e não por algum parâmetro de localização, de extensão, de origem ou de identidade.

Lo que confiere a un lugar su especificidad no es ninguna larga historia internalizada sino el hecho que se ha construido a partir de una constelación determinada de relaciones sociales, encontrándose y entretejiéndose en un sitio particular. Si nos desplazamos desde el satélite hacia el globo, manteniendo en la cabeza todas estas redes de relaciones sociales, movimientos y comunicaciones, entonces cada "lugar" puede verse como un punto particular y único de su intersección. Es, verdaderamente, un punto de encuentro. Entonces, en vez de pensar los lugares como áreas contenidas dentro de unos limites, podemos imaginarlos como momentos articulados en redes de relaciones e interpretaciones sociales en los que una gran proporción de estas relaciones, experiencias e interpretaciones están construidas a una escala mucho mayor que la que define en aquel momento el sitio mismo, sea una calle, una región o incluso un continente. $\mathrm{Y}$ a su vez esto permite un sentido del lugar extrovertido, que incluye una conciencia de sus vínculos con todo el mundo y que integra de una manera positiva lo global y lo local (MASSEY, 1991, p. 126).

O lugar, portanto, é pensado como um ponto de encontro de fluxos e trajetórias que se redefinem justamente no encontro com outros fluxos copresentes. O lugar é entendido como algo inapreensível — seja através de palavras, seja através de imagens , como algo inacabado que nos convida a perceber (e agir em) processos. Nesse sentido, não nos é possível captarmos o espaço no instante em que apertamos o botão de gravar da câmera. Ao estarmos em um lugar com uma câmera — e tudo o que ela carrega de força

\footnotetext{
${ }^{6}$ A cineasta Agnès Varda é uma referência para pensarmos o acaso na dimensão criativa. Temos trabalhado com isso por querer que o cinema escape da ideia de representação da verdade e, em grande medida, possa estar mais próximo da ideia de criação - ainda que em muitos casos ele crie a verdade da filmagem. Ela nos chama atenção ao convergir a ideia de acaso, criação e afetividade "É o acaso que faz com que eu proponha, que o filme não seja uma verdade, que seja uma proposta que você aceita ou não", diz referindo-se à "afetividade” (VARDA apud FURLANETO, 2009).

${ }^{7}$ Em fluxo permanente, aberto, múltiplo, temporário.
} 
criativa - ingressamos nos fluxos espaciais para com eles produzir novas conexões e outras variações deste lugar através das imagens. As próprias imagens são variações espaciais daquele lugar — uma sala de aula, um pátio, um refeitório, um quarteirão, uma cidade, um país. As imagens não registram este lugar, mas agem ali ao registrar parcelas dele com forças e intensidades distintas daquelas que possuem fora da imagem, deslocando aquele lugar dele próprio ao produzirem sutis variações em suas trajetórias, o corpo acoplado a uma câmera sendo uma delas. Assim, assumimos o caráter relacional entre a câmera e as forças humanas e inumanas que compõem o arranjo espacial de cada lugarescola.

Isto é a eventualidade do lugar, em parte, no simples sentido de reunir o que previamente não estava relacionado, uma constelação de processos, em vez de uma coisa. Este é o lugar enquanto aberto e enquanto internamente múltiplo, não capturável como um recorte através do tempo no sentido de um corte essencial. (MASSEY, 2008, p. 203).

Não estamos filmando a escola ou o que acontece dentro dela, estamos sim filmando com a escola, intervindo naquele lugar ao deixar nossos corpos-câmeras ${ }^{8}$ serem afetados pelas demais trajetórias que já o compunham na certeza de que algumas delas tornar-se-ão potências espaciais para o cinema que emergirá ali.

Essa expressão busca apontar o espaço como potente na oferta de experiências e encontros nos quais emergem outros tipos de imagens, justo por elas terem sido gestadas em estilos e dispositivos cinematográficos que se abrem para os acasos e exigências singulares que as experiências e encontros espaciais impõem ao cinema em cada lugar do qual ele se aproxima sem roteiros prévios ou com roteiros que se voltam não para a produção das imagens e sons, mas para a produção de encontros e experiências onde imagens - quais? - poderão - talvez - vir a configurar-se de outras maneiras - surpreendentes? - fazendo outros o cinema e o lugar. (OLIVEIRA JR, 2016, p. 69)

Certamente o cinema que emerge nestas condições não é o cinema habitual que conhecemos, com tudo extremamente planejado, roteiros definidos, cenários em estúdios, cenas e iluminação executadas e controladas por profissionais etc. Não fazemos um cinema industrial, mas um cinema pós-industrial (MIGLIORIN, 2011), ou melhor dizendo, um cinema expandido, especialmente em suas múltiplas tensões e articulações com os equipamentos digitais de produção de imagens e sons.

Nos últimos anos o cinema vem expandindo-se tendo como um de seus apoios as possibilidades das longas gravações em vídeo, permitindo artistas a deixarem-se levar pelo acaso dos encontros no espaço vivido e, a partir deles, junto com pessoas e paisagens encontradas, criarem situações de interação, de composições fílmicas através das negociações que surgem entre o cinema (equipe, câmeras, cultura audiovisual...) e a "constelação de trajetórias" (MASSEY, 2008) encontradas naquele lugar. Nesses encontros no espaço o cinema vem inventando filmes que arrastam

\footnotetext{
${ }^{8} \mathrm{Na}$ expressão corpo-câmera dobra-se uma perspectiva conceitual (LEITE, 2015; LEITE; CHISTÉ, 2015) de que não filmamos apenas com os olhos, mas também (e talvez principalmente) com as mãos, com as vísceras, com os pés e joelhos, enfim, com todo o corpo que, ao ter acoplado a si uma câmera, passa a compor um híbrido em que ambos se metamorfoseiam ao se afetarem mutuamente: corpo-câmera que, por isso, liga-se e desliga-se conjuntamente.
} 
para si as pessoas e paisagens encontradas, impondo a elas devires cinematográficos, devir-personagem, devir-cenário (OLIVEIRA JR, 2016, p. 68).

$\mathrm{Na}$ citação acima está explícita a direta relação entre o acaso e aquilo a que temos chamado potências espaciais para o "nosso" cinema, aquele produzido nas escolas, nas condições efetivas que cada lugar-escola possui no momento que o cinema ali aporta.

Um cinema que, para ser potente, implica estar ali atento aos modos de intervir e disparar processos no lugar. Processos que venham a fazer emergir devires naquele lugar, devires do lugar enquanto imagens de cinema, alterando e modificando os arranjos espaciais a partir da presença da câmera. E o que dispara processos para todos os lados nessa relação entre lugar-escola e cinema? Acasos. Acasos que não são pensados como coincidências, mas sim como vãos abertos no lugar, como oportunidades para tornar sensíveis parcelas antes insensíveis daquele lugar. Acasos, portanto, como forças de criação, como encontros alegres.

Assim, é importante salientarmos que o lugar pode ser encarado como um conjunto de acasos que nos permitem encontros inusitados com a criação. Em se tratando das imagens de cinema como nosso objeto principal, podemos assumir que é possível pensarmos em quais circunstâncias esses acasos nos permitiram criar, tanto imagens quanto pensamento. Gostaríamos de seguir com isso em mente para que fique claro que nosso texto versa, principalmente, na relação entre o cinema, o lugar e os acasos que nos abriram um campo de possíveis.

\section{Os encontros alegres no lugar-escola}

\section{Encontro com um oficineiro e algumas/uns jovens estudantes e...}

Filmar é produzir imagens com aquilo que acontece no instante da filmagem. Filmar é uma espécie de encontro e isso pode se dar de diferentes maneiras. Em um estúdio, com ambientes mais ou menos controlados, esses encontros podem até ser planejados. Na escola, ambiente volátil e aberto, apesar de todo desejo de controle, isso se dá de modos muito mais imprevistos e improvisados.

$\mathrm{Na}$ oficina realizada com jovens entre 13 e 15 anos $^{9}$ passamos cerca de nove meses trabalhando exclusivamente com documentários de Eduardo Coutinho ${ }^{10}$ antes de adentrarmos em um universo de negociações e pequenas produções audiovisuais que resultaram no filme Saber/Poder ${ }^{11}$, título dado pelas/os estudantes-cineastas.

Nosso foco era no método de entrevistas desse diretor, ou seja, conversar com pessoas da escola com uma câmera na mão e algumas perguntas acerca de um tema de interesse dos alunos na cabeça. Ao longo da oficina e das experimentações-entrevistas

\footnotetext{
${ }^{9}$ Dois meninos e três meninas, inicialmente; após alguns ocorridos ficamos em um menino e duas meninas.

${ }^{10}$ Consagrado documentarista brasileiro, autor de filmes importantes como "Cabra Marcado para Morrer" e "Edifício Master”. Em um texto escrito pelo próprio diretor, há uma fala que nos interessa e que resume, em grande medida, aquilo que buscarmos fazer na oficina realizada com os jovens: "O improviso, o acaso, a relação amigável, às vezes conflituosa, entre conversadores dispostos, em tese, dos dois lados da câmera - esse é o alimento essencial do documentário que procuro fazer." (COUTINHO, 2013, p. 16).

${ }_{11}$ Disponível em: < https://www.youtube.com/watch?v=F8JqW-VRC o $>$. Acesso em: 20 nov. 2020. Por questões éticas decidimos não disponibilizar o vídeo de modo aberto na internet. Tendo em vista seguir os acordos traçados entre nós, a escola e as/os participantes, apenas pessoas com o link e mediadas por algum contexto de pesquisa devem acessar.
} 
fomos extraindo algumas técnicas de Coutinho para pensar e continuar a produzir o filme. A forma como filmamos e editamos, apesar de partir de concepções estéticas desse diretor, foram ganhando materialidade nos possíveis criados por nós. Foram felizes acasos que nos forçaram a cair em seu vão, nos forçaram a um saber-fazer particular daquela situação.

O filme em questão contribuiu para pensarmos como as imagens antes mesmo de serem feitas ou quando vistas na tela grande - tornadas cinema - oferecem questões acerca das relações no espaço escolar e parecem ter sua força naquilo que são capazes de nos fazer conversar dentro da escola.

Inicialmente, logo depois de acordado com a direção da escola como trabalharíamos, e tendo como referência o estilo cinematográfico de Eduardo Coutinho, nossa prática consistiu em experimentar pequenas filmagens com celulares dentro da escola, na qual o uso de celulares é proibido. A ideia era termos um acervo para conversar sobre o que estas filmagens nos ofereciam como questões. Brincávamos com a câmera com o intuito de experimentar alguns "dispositivos de criação de imagens"12 — Minuto Lumière, Filme Carta, pequenas entrevistas, etc.

O seguimento com a produção do filme avançava, e, a medida que as imagens iam sendo feitas, as assistíamos juntos e a conversa sobre elas desencadeava a vontade de filmar ainda mais. Sempre surgiam questões sobre como as entrevistas haviam ocorrido e como fariam diferente nas próximas. Eram mínimos os detalhes que supunham modificações: o jeito de segurar a câmera, quem faria as perguntas ou quais personagens entrevistar. Nossas negociações sobre como filmar ou o que filmar foram ganhando ritmo aos poucos, a partir daquilo que emergia das próprias filmagens feitas por aquelas/es jovens estudantes. Apesar de serem mínimos detalhes enquanto ajustes técnicos, nossa aprendizagem era grande. Especialmente pelas longas conversas e pelo modo como nós, oficineiro e participantes, íamos percebendo nossas intervenções, como corpos-câmera, naquele lugar. O modo como íamos compondo com as trajetórias e forças ali presentes - as/os professores/as, os/as demais estudantes, o controle, o medo, a indignação, a insubmissão/submissão, o pátio, o intervalo, o sinal, a situação de prova, o momento do hino, etc. Trajetórias e forças humanas e inumanas naquela constelação temporária que constituía aquele lugar-escola.

Um dos participantes, em dado momento, comete uma infração escolar e é impedido de participar da oficina - um acaso que perturbou logo de cara nossa configuração. Diante de tal fato, sabendo do impedimento daquele estudante, mas não do motivo pelo qual havia sido punido, solicitamos a ele que tentasse fazer um filme sobre o assunto e nos enviar por grupo de whatsapp para conversarmos sobre as imagens. A direção escolar nos chamou em seguida para uma conversa bem clara, que, em resumo, colocava limites sobre o que o oficineiro, como profissional externo à escola, poderia pedir ou não para as/os estudantes fazerem. Ao mesmo tempo, a direção expôs certas fragilidades do ambiente escolar, levando-nos a aprender como lidar com algumas questões diante de nossa inquietante curiosidade.

Foi oferecida uma oficina de hip hop na escola no mesmo horário de oficina de cinema, algo que não fazia parte do planejamento inicial e que se tornou um acaso competidor. Os/as poucos/as estudantes da oficina ficaram divididas/os. Alguns

12 Um dispositivo de criação seria “a introdução de linhas ativadoras em um universo escolhido. Ele pressupõe duas linhas complementares: uma de extremo controle, regras, limites, recortes: e outra de absoluta abertura” (MIGLIORIN, 2015, p. 79). 
encontros foram solitários e desanimadores. A sensação era a de que o trabalho por ali gerava insegurança na gestão e, ao mesmo tempo, era insuficiente para criar vínculo com as/os participantes. Foi então que, num encontro que havia sido pensado para ser o fim da oficina, dois participantes - uma jovem e um jovem - fizeram a proposta de produzirmos um filme: uma produção de cinema com cronograma e investigação de um tema.

Foi aí que o argumento do filme Saber/Poder surgiu, no contexto de acasos que ora nos desassossegavam e ora nos inspiravam. Em ambos momentos o que tínhamos diante de nós eram acasos de intensidade alta, verdadeiros vãos abertos no tecido da relação entre cinema e escola devido à conexão de certas trajetórias que hora reduziam a velocidade dos encontros alegres e hora acelerava a velocidade ao promover múltiplos encontros de alegria intensa. Um modo alegre de percebermos os desassossegos - incômodos diante daquilo que nem sempre funciona como a gente espera. Alegre porque desloca a ideia de desassossego do lugar de "raiva" e o recoloca num lugar de movimento, de forçar a agir, de impulso vital para que um outro processo ganhe vida.

Quando efetivamente iniciamos as filmagens para o filme, havia uma regra de filmagem que dizia, à maneira de Coutinho, que não poderíamos filmar a mesma pessoa duas vezes. Era a linha dura do dispositivo de criação de imagens que decidimos experimentar. Isso nos forçava a ter que lidar com toda a espécie de acaso diante da câmera. Isso nos forçava a compor com os acasos e as potências de não saber ao certo o que viria. Íamos lá e filmávamos uma única vez aquela entrevista, não podíamos repeti-la. O que a pessoa dissesse era o material e ponto final.

Apesar de parecer rígido era apenas uma aposta, a de que o momento da filmagem deveria ser nossa matéria prima para pensar as possibilidades do filme. Aprendíamos que o mais bacana era ir fazendo e conversando, de modo que todo o tipo de acaso pudesse ir nos afetando e com eles íamos criando nosso próprio modo de filmar. Aprendíamos com o acaso de pessoas falando atrás da câmera. Com o fato de estarmos entrevistando alguém e, de repente, a pessoa mudar totalmente o foco da conversa para falar algo que ela gostaria de dizer para a câmera, para as/os jovens estudantes-cineastas. Não tínhamos um roteiro. Ao contrário, tínhamos uma única pergunta, “Como são criadas as regras desta escola?", que íamos fazendo e desdobrando em outras de acordo com as respostas. Finalizadas cada entrevista, seguíamos conversando e fazendo outras mais.

Orlandi (2010) nos oferece uma ideia muito interessante para conversar com imagens, escola e acasos, que nos faz repensar um pouco nossa prática: “[...] o caos é o inimigo aliado do pensar" (ORLANDI, 2010, p. 150). Talvez porque para que um pensamento aconteça seja necessária alguma instabilidade, algum distúrbio. Que instabilidade é essa que as imagens estão a nos oferecer na escola e que exige de nós pensamento? A instabilidade de um fazer experimental e os perigos que dele emanam. Insegurança do que pode acontecer quando jovens e seus celulares estão a circular por espaços onde o poder de vigiar é frágil. Desassossegos que abrem passagens.

\section{Encontro com uma professora e duas crianças pequenas e...}

Gritos e batidas fortes chamaram a atenção do corpo-câmera da professora das crianças de menos de dois anos. Da posição onde estava mirou a câmera na direção onde 
dois meninos brincavam na casinha de plástico, um do lado de dentro e outro do lado de fora. Um empurrava a janela para abrir e o outro para fechar. A cada abertura/fechamento um estrondo e um grito-riso. A professora acompanhou o desenrolar de toda esta brincadeira, buscando os melhores ângulos para fazer isto e mostrar, em imagens e sons, o que ali ocorria: algo arriscado, pois a janela, quando abria, poderia machucar o garoto que estava fora e poderia bater no garoto que estava dentro quando era empurrada de volta com toda força.

A seguir, o desenlace da história: quem estava fora desloca-se para o lado onde está a porta da casinha e, ao entrar nela, encerra a brincadeira, mas não a filmagem, a qual se encerra segundos depois quando o garoto olha para a câmera, abre a porta e grita, mas com muito menos intensidade que antes, quando empurrava a janela contra a parede da casinha e o garoto que estava dentro dela. A professora-cineasta afirma que

[...] a filmagem inicial era um plano-sequência um pouco mais longo. A decisão de cortar foi devida ao meu entendimento de que, após a cena que encerra o filme, a intensidade da situação filmada se reduzia. A cena do garotinho fechando a porta após ter entrado na casinha me pareceu trazer para o filme um final mais intenso" (Trecho do caderno de campo de Rozeli Lemos de Melo - outubro 2019 - Acervo do Projeto "Lugar-escola e cinema: afetos e metamorfoses mútuas")

Além disto, o filme "Só rindo"13 não apresenta o mesmo enquadramento da filmagem original, uma vez que houve a aproximação digital da cena, realizando um novo enquadramento que intensifica a cena na medida mesma que a recorta da dispersão de outras cenas que aconteciam no seu entorno.

O que vemos, portanto, é e não é o registro do lugar onde a cena ocorreu. Se podemos afirmar que ela é o registro porque ali estão cores e formas e personagens reconhecíveis no lugar-escola, nas imagens que vemos as trajetórias da casinha e das crianças aparecem intensificadas, o que altera o modo como elas nos afetam, fazendo com que sejam muito mais devires cinematográficos do lugar do que propriamente a representação deste lugar e seus elementos.

Se num primeiro momento, podemos dizer que o acaso que atravessa este filme foi o da coincidência temporal e espacial da professora estar ali com a câmera ligada e pôde volta-la para o local onde a brincadeira se passava, o acaso-acontecimento que vemos no filme não é só este, mas é também, e principalmente, o amálgama de gestos criativos do cinema - corte inicial e final, aproximação do enquadramento, inserção de música - que fizeram do pequeno plano-sequência um potente filme que nos traz um bloco de emoções variadas e intensas acerca da vida que é vivida naquele lugar; uma vida vivificada pelo acaso do filme.

Ao contrário de uma esperada tranquilidade com os usos de cinema na escola, o que alguns autores vêm trazendo em suas pesquisas diz de uma potencialidade que certos riscos oferecem ao ambiente escolar. Como algo que nos forçaria necessariamente a ter de lidar com o fora de uma vida protegida e regulada. Justamente o que nos invade, empurrando-nos em um constante inventar de outras saídas para o já conhecido. Cesar Leite e Rafael Christofoletti (2015), por exemplo, em algumas de suas experiências com

\footnotetext{
${ }^{13}$ Disponível em: < https://www.youtube.com/watch?v=fCyjw-wt8Kg\&t=7s >. Acesso em: 04 mai. 2020.
} 
cinema e infância, atentam-se para o ambiente escolar como um local onde a arte se produz no fluxo dos acasos e das incertezas: “[...] [e]ntre riscos e perigos acabamos sempre nos colocando em trânsito, entre zonas de perigo, entre faixas de tensão, entre um não ser de um lugar e nem de outro, o risco de não ser, o perigo da eterna estrangeiridade." (LEITE; CHRISTOFOLETTI, 2015, p. 49). É disso que queremos tratar aqui, dos processos em torno de um saber e um não saber quando o cinema estrangeiriza ${ }^{14}$ a escola e a escola estrangeiriza o cinema.

Diante disso, é justo questionarmos como temos lidado com aquilo que, de tão arriscado, nos coloca medo. O que se pode filmar na escola e o que não se pode? Como filmar? Posso compartilhar imagens entre amiges?

Assumindo a produção de imagens como praticamente inevitável na educação escolar de uma sociedade cada vez mais constituída por imagens e aparelhos produtores de imagens, nos perguntamos como podemos aproveitá-las para criar novas oportunidades de pensamento e conhecimento. Temos entendido que tais imagens, para além do registro que já é marca dos modos habituais de como lidamos com as câmeras, funcionam também como um gesto no mundo capaz de criar algum distúrbio nestes hábitos de registrar. Importante notar aqui que o gesto disruptivo é realizado pela imagem e não propriamente pelo sujeito que a produziu. Ou seja, uma imagem pode vir a ser algo que faz com que o próprio mundo (a escola) estremeça, ainda que de modo sutil, e, ao fazê-lo, faz emergir processos que até então não eram possíveis de acontecer ali. Por exemplo, quando um/a estudante qualquer resolve caminhar pelo pátio com a câmera ligada, mostrando para todes o que está fazendo, atravessando a passos lentos uma distância razoável, dizemos que algo aconteceu não apenas porque uma câmera filma, mas, principalmente, porque, ao filmar, todo o conjunto de relações humanas por ali se altera em virtude do fato. Se a alteração do lugar (dos demais gestos e trajetórias que ali ocorriam) é nítida, ou mesmo tácita, não nos interessa tanto, uma vez que o que nos importa é o que fazer com isso depois, com as imagens - (não) registros - do lugar e com as dobras delas como potência disruptiva dos modos habituais como os sujeitos humanos agem no lugar, estando ou não com uma câmera na mão.

Temos feito isto principalmente através de oficinas de experimentação cinematográfica realizadas nas próprias escolas. Neste texto, nos concentramos em apenas duas destas escolas, nas quais se realiza(ra)m as pesquisas aqui focadas. Nas histórias e produções do já citado Programa Cinema \& Educação, há muitas outras escolas onde "o acaso rola solto" e faz emergir um estilo de cinema que ainda não tem nome. Parafraseando Cao Guimarães ao nomear seu estilo de cinema de cožinha, pois a cozinha é uma "[...] oficina de experimentos, liberdade de expressão que produz cheiro e saliva, felicidade fácil provida pelos sentidos" (GUIMARÃES, 2008, p. 1), poderíamos nomear o "nosso" cinema de

\footnotetext{
14 Aqui temos que colocar muita atenção ao termo estrangeiro na relação com a escola. Algo comum a muitas pesquisas, o que causa uma certa desconfiança às/aos trabalhadoras/es escolares, diz respeito a lidar com o estrangeiro como sendo aquele/a que, sendo de fora da escola, adentra-a e causa-lhe o desassossego necessário à mudança. Não é essa a aproximação que fazemos ao termo, e que julgamos fundamental às questões que temos traçado para estas pesquisas. Estrangeiro aqui aproxima-se da noção de virtual, intensamente trabalhada nos estudos de Henri Bergson e posteriormente potencializado por Gilles Deleuze. Ou seja, estrangeiro não como algo externo ao lugar, mas completamente inerente a ele. $\mathrm{O}$ atual como produto de seu fora (o virtual). "O atual é o complemento ou o produto, o objeto da atualização, mas esta não tem por sujeito senão o virtual. A atualização pertence ao virtual.” (DELEUZE; PARNET, 1996). Disponível em: <https://antropologiassociativa.files.wordpress.com/2010/06/deleuze 1996 oatual-e-o-virtual bookchapt.pdf $>$. Acesso em: 26 jan. 2017.
} 
cinema de escola - e não cinema escolar -, pois a escola é também um lugar de experimentos, repositório de expressões que produzem imagens e sons repletos de sensações e aprendizados?

\section{Os encontros alegres nas imagens}

\section{Encontro entre as imagens e sons de um filme e o saber/poder da escola e...}

Há uma espécie de encontro que ocorre com as forças emergentes das próprias imagens. São encontros audiovisuais. Instantes, às vezes, que numa fração de segundo podem fazer nascer processos. Às vezes mais demorados, no alongamento que as imagens demoram pra fazer acontecer algo. Às vezes não acontece nada também, e, ainda assim, acreditamos numa pulsão de alegria com as imagens. Podemos afirmar isso por enxergar que em todos esses (a)casos há algo em torno de uma aprendizagem importante da relação do cinema com a escola. Observemos algo em torno do filme realizado na escola e o que nos encontrou.

No caso do filme "Saber/Poder", um exemplo estético forte - e fomos questionados disso - foi o fato do rosto das personagens aparecerem cortados. Havia uma preocupação que nos surgiu no processo de filmagem: "e agora, a gente identifica a pessoa que falou aquilo?”. "Mas por que?” perguntava uma pessoa da plateia em um evento realizado na Unicamp ${ }^{15}$.

Algumas respostas, retiradas dos escritos presentes no caderno de campo do pesquisador por ocasião deste evento, nos mostram um pouco desta conversa:

(N) "Fazíamos as filmagens sempre buscando não revelar totalmente o rosto de quem estava falando, apesar das pessoas ali saberem quem eram os entrevistados."

(E): "A gente sabia que podia dar rolo, por isso a gente queria sempre que o filme fosse visto na nossa presença, pra poder trocar ideia e esclarecer as coisas [...]. A gente não queria fazer inimigos, queríamos ouvir e filmar as pessoas sobre algo que incomodava, isso fez a gente pensar melhor como as regras são criadas na escola, e, também como precisávamos ter as nossas próprias regras para o filme existir". (Trechos do caderno de campo de Eduardo de Oliveira Belleza - outubro 2018 Acervo do Projeto "O documentário e a escuta sensivel do lugar: quando escola e cinema formam um povo")

Por algum tempo, a câmera tornara-se um instrumento de poder na mão daqueles/as realizadores/as. Isso também os/as forçava a ter que pensar como lidar com esse poder. Ao mesmo tempo tinham que pensar com os acasos gerados pelas imagens que faziam e como isso mobilizava questões na escola.

Há uma ética muito produtiva nisso. Algo que nos ensina a buscar o melhor daquilo que produzimos, e, temos entendido com essa experimentação, que o melhor é justamente não fazer desavenças, mas, ao contrário disso, permitir que o máximo de pessoas possam ver nosso trabalho, pensar com ele, ainda que o filme incomode. Assim como Massey (2008) nos convida a pensar o lugar como um conjunto de trajetórias

\footnotetext{
${ }^{15}$ Evento para apresentação do filme em que as/os próprias/os jovens conversavam conosco. Ocorrido em outubro de
} 2018, numa sala de aula da Faculdade de Educação, transformado em espaço de empoderamento juvenil. 
(humanas e inumanas) em constante atualização, lidávamos com a trajetória de denúncia dos rostos das personagens sem apagar suas marcas expressivas. Ao contrário, evidenciando-as em close para extrair dali algo que pudesse atingir o público - bocas, olhos, expressões faciais, movimentos de mãos, etc. É possível dizer que negociamos com o espaço (as trajetórias existentes: institucional, identitária, etc), mas, experimentamos mesmo foi com os devires, com os acasos, com as intuições.

Quando as imagens foram vistas na tela grande da sala de informática, aqueles closes chamaram a atenção. A partir daí os incômodos vieram à tona de maneira mais intensa. Isto se deu principalmente porque entrevistados e entrevistadas, ao se reconhecerem no filme, não se sentiram propriamente confortáveis com suas imagens, uma vez que, mesmo sendo elas apenas fragmentos mínimos de seus rostos, ao acoplarem-se com as vozes ouvidas simultaneamente eram facilmente reconhecíveis pelos/as frequentadores/as da escola.

Se estes incômodos foram rapidamente percebidos nos/as alunos/as-personagens do filme, foi perceptível também o quanto nossas imagens produziram desassossegos para as/os profissionais de educação na escola. As imagens e palavras de "Saber/Poder" abriram brechas para que a escola tivesse que conversar sobre as regras que ela mesma estabelecia e, nesse sentido, desencadearam processos para lidar com o que emerge da relação entre escola e cinema, para lidar com os acasos que esta relação inevitavelmente provoca.

São processos que, num primeiro momento, incomodam, mas que se mostram potentes por fazer movimentar certas durezas presentes nas escolas. Por exemplo, os desassossegos gerados pelo filme foram disparadores de um convite feito pela gestão da escola, para que as/os estudantes-cineastas participassem da produção das regras da escola no ano seguinte. Ainda que houvesse incômodos e riscos, havia também uma vontade grande de usar aquilo em favor da própria escola, no sentido de produzir outros percursos para a questão das regras e dos afetos que elas criavam. Consideramos este um exemplo marcante daquilo que temos chamado de encontros alegres com as imagens.

\section{Encontros entre as imagens e sons de filmes e o deslugar que elas criam e...}

A câmera parada tem sido um estilo de filmagem bastante utilizado nas primeiras experimentações com o cinema na escola, buscando apontar às/aos professoras/es outras possibilidades de filmagens que não o acompanhamento, com a câmera na mão, de alguma ação que se desenrola. Buscando, portanto, experimentar outros modos de fazer cinema que não o habitual. Estas experimentações com câmera parada nos deram a ver um lugar antes inexistente. Trazemos a este texto o exemplo de dois pequenos filmes onde algo emergiu das imagens (e sons) como um acaso: "Quem quer casar e Fogo".

Em ambos a câmera havia sido colocada em algum local do pátio da escola durante o período em que as crianças brincam livremente nele. É comum fazermos isto, experimentando as possibilidades do campo filmado e do extracampo.

No filme "Quem quer casar", a música que dá título ao filme é ouvida por nós, mas não vemos as crianças que cantam. Intuímos estarem ali ao lado, no extracampo próximo de onde estava a câmera. Mas onde estaria a câmera (e as crianças) para girar assim? Nas

${ }_{16}$ Disponível em: < https://www.youtube.com/watch?v=uCL4qNmy 0I>. Acesso em: 04 maio. 2020. 
imagens só vemos um giro constante de copas de árvore que, aos poucos, provoca certa (ou muita) tontura e desconforto em quem mira a tela. Imagens do alto são vistas à nossa frente.

As sensações provocadas por estas imagens foram obra do acaso? Entendemos que o acaso é sempre participante, por mais que nosso planejamento e controle estejam ali e também formem linhas de segmentação para os processos criativos. Como no exemplo da professora que tinha diante de si a tarefa de realizar filmagens a partir do dispositivo Minuto Lumière e buscou, no parque da escola, um local onde colocar a câmera parada durante um minuto. Escolheu colocá-la sobre o eixo do brinquedo gira-gira onde um grupo de crianças brincava de cantar e girar simultaneamente. A realizadora do filme não fazia uma ideia precisa de que imagens estava captando. Sabia que captaria copas de árvores, mas não sabia de que maneira estas imagens apareceriam e iriam afetar as/os espectadoras/es. Somente quando projetadas na telona da sala de cinema da escola, as forças que as atravessam se fizeram notar, inclusive por quem as realizou.

$\mathrm{O}$ acaso no filme "Fogo" "17 não emergiu das imagens, mas sim dos sons (em sua composição com as imagens). A realizadora havia feito algumas filmagens no parque da escola em câmera parada, colocada no chão e direcionada para grupos de $\operatorname{crianças~}^{18}$ que brincavam de acender fogo com gravetos (sem que qualquer fagulha ocorresse a não ser em suas férteis imaginações). Após decidir montar este pequeno filme com dois fragmentos destas filmagens, a professora foi em busca de sons para compor com elas, uma vez que a maior parte dos sons captados durante aquelas filmagens eram atravessados por falas e ruídos não desejados por ela em seu filme. Decidiu por utilizar um pequeno trecho gravado em uma das filmagens e, ao inseri-lo na linha de edição de seu celular, replicou-o várias vezes até o final da duração do filme (bem maior que a duração do trecho sonoro) e compartilhou-o no grupo de whatsapp do Cineclube Regente/Cha.

Ao assistirmos ao filme nas telas de nossos celulares, as falas das crianças, repetidas muitas vezes - sempre as mesmas e sempre outras, vão tendo seus sentidos alterados: de falas realistas captadas no exato momento da ação vista irão se tornando signos sonoros do cinema, desvinculados da cena vista e ao mesmo tempo conectados com aquilo que vemos (a brincadeira de acender fogo com gravetos), gerando sensações de ambiguidade e exasperação nos espectadores de seus pouco mais de 3 minutos.

Em ambos os filmes as forças que pulsam não são obras das intencionalidades de suas realizadoras cinematográficas, mas sim descobertas que ocorreram no momento em que os filmes foram vistos, seja projetado na telona ou acompanhado do início ao fim em telas de celular. Encontros alegres, promovidos pelo acaso, que ampliaram a potência destes filmes, os quais, a despeito de serem produções antigas, seguem sendo lembrados nas conversas sobre cinema na escola.

\footnotetext{
${ }_{17}$ Disponível em: <https://www.youtube.com/watch?v=X6ECXdcw98o $>$. Acesso em: 04 maio. 2020.

${ }^{18}$ Nas embaçadas cenas que compõem o filme vemos somente meninos; todos com idade de cerca de três anos, com várias cores e tons de pele.
} 


\section{Conclusões}

Nos parece interessante defender a ideia de um cinema sendo produzido sem muito planejamento, além de experimentar modos diversos de filmar ou de assistir filmes de um diretor, procurar fazer algumas filmagens com celulares e conversar muito. À medida que isso vai abrindo portas para outras produções cinematográficas, numa relação mais íntima com câmeras e programas de edição, podemos alçar voos em outras direções. Como no caso dos jovens que, partindo de alguns filmes de Eduardo Coutinho e de alguns exercícios simples de filmagem (minuto Lumière, filme carta), acabam produzindo um média metragem, inspirados em fazer movimentar aquilo que já era uma força atuante no espaço escolar (as relações de poder), mas que precisava ganhar existência através das imagens para fazer emergir outros olhares.

É a partir disso que temos trazido a ideia de um cinema pós-industrial, mais vinculado a um fazer experimental com as forças que nos chegam do lugar. Poderíamos até sugerir, se o leitor preferir, a ideia de um cinema de encontros com o lugar. Um cinema que nasce das negociações com o lugar e não com um roteiro prévio. É com essa ideia que temos enxergado a relação entre o acaso e as potências espaciais presentes em qualquer local onde o cinema aporta. Em grande medida, nossa busca tem sido perceber como isso aponta para um tipo de cinema que emerge daquilo que pulsa na escola, ou seja, um cinema que acontece com a vida do lugar, que abre passagens, que converge trajetórias humanas e inumanas através das imagens.

Não sabemos, portanto, o que o encontro entre cinema e escola irá nos levar a experimentar, nem mesmo se será um filme. Pode ser que este modo de fazer cinema prescinda do filme, mas certamente não prescinde das experiências que o fazer cinema imprime no lugar-escola.

Fato é que há nisso tudo uma força de desterritorialização dos processos homogêneos de ensino no espaço escolar quando experimentamos outras formas de ver e fazer imagens. O cinema, entendido como um corpo estranho produtor de virtuais estrangeiridades, age e produz acasos no cotidiano escolar, em grande medida por não haver um saber fazer prévio para que o cinema instaure ali outras práticas escolares. Isto faz com que a própria escola entre um estado de atualização constante devido a este modo de fazer cinema que nela se efetiva através de encontros instáveis.

Nesse sentido, é que entendemos o teor da palavra “caos", empregada por Orlandi (2010), que nos fascina no trato com as imagens na escola. O caos como uma potência de fora que as imagens carregam, região de possíveis porvires que estão aí para inventar outros arranjos sociais, demandando outros modos de estar docente, de estar estudante, de estar humano.

Imagens que, de repente, nos convocam a lidar com o caos daquilo que foi gestado através dos desejos com a câmera, na relação com as forças humanas e inumanas que formam aquela constelação temporária de trajetórias que configuram um lugar-escola. Desarticulando práticas educativas para que outras coisas aconteçam. Não sem os riscos de termos que lidar com o novo e com os perigos que ele carrega. Não sem compor com os acasos e desvios que qualquer nova linha de criação possa fazer emergir: ter que cortar rostos por questão de exposição das identidades, criar um modo de estar presente quando 
for conversar sobre o processo de produção, compor imagens e sons que não se sabe ao certo como irão afetar os/as espectadores/as, acolher pensamentos e falas de modo sensível a um deixar falar que produz afetos, questões, problemas.

Mas não só o cinema tem esta potência, também a escola com toda sua produção desejante, sua força de invenção age para que outras imagens possam povoar de saberes um mundo em atualização no cinema e seus filmes.

Temos vislumbrado que o tipo de cinema que temos experimentado nas escolas não é algo tranquilo, fácil de se fazer, ágil em sua execução. Muito pelo contrário, seu ímpeto está em não ser algo pronto e acabado para ser aplicado e regulado, mas sim um processo em aberto, inconstante. Uma arte de compor (com os) acasos e criar ritmos... e, também, de gestar mundos possíveis para que outros processos possam acontecer e continuar nos movimentando: invenções a partir daquilo que nos força a pensar, que nos força, portanto, a criar. O que isso nos ensina? Talvez que seja possível uma outra concepção de educação emergindo da relação cinema e escola, constituindo outros saberes e práticas com as imagens. Uma educação que acontece através dos encontros alegres. Cinema e escola se tocando e inventando-se outros. A própria escola, enquanto lugar, podendo ser percebida de modo mais sensível e múltiplo. Um cinema dos corpos humanos acoplados às máquinas e da mecânica que acontece neles. Educação das singularidades, diríamos.

Isso nos parece ter força o bastante para defendermos que não podemos encerrar os processos pelo medo de arriscar, apostando que há nesse risco um tanto de abertura para colocarmos outras questões necessárias à escola e ao cinema. Essa é, ao nosso ver, uma das forças dos acasos na educação. A de nos fazer acontecer de outras maneiras. Com/pelas/através das imagens. Precisamos continuar a pensar com outras imagens, outros acasos, outros processos. Um tanto de cinema e outro tanto de escola emergindo daquilo que não se sabe, carregado de experiências com as imagens e sons, com as forças humanas e inumanas em atualização permanente no lugar-escola.

\section{Referências}

BELLEZA, E. O. O documentário e a escuta sensível do lugar: quando escola e cinema formam um povo. 2019. 319 folhas. Tese (Doutorado em ) - Programa de Pósgraduação em Educação, Universidade Estadual de Campinas, 2019. Disponível em:

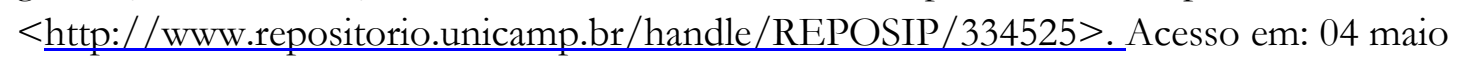
2020.

COUTINHO, E. A verdade da filmagem. In: OHATA, M. (Org). Eduardo Coutinho. São Paulo: Cosac Naify, 2013. p. 14-20.

ESPINOSA, B. Ética. Lisboa: Relógio D’água, 1992.

DELEUZE, G. Espinosa: filosofia prática. São Paulo: Escuta, 2002.

DELEUZE, G.; PARNET, C. Dialogues. Paris: Flammarion, 1996. 
FURLANETO, A. Faço cinema com o acaso, diz Agnèz Varda. Folha de São Paulo, São Paulo, 28 set. 2009. Disponível em:

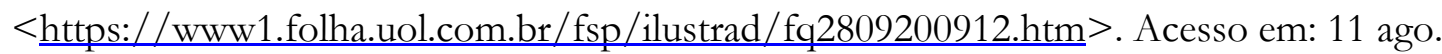
2020.

GUIMARÃES, C. Cinema de Cozinha. Texto escrito para a Mostra Retrospectiva "Cinema de Cozinha”, exibida no SESC SP e SESC Vila Mariana, em São Paulo. 2008.

Disponível em: <http://www.caoguimaraes.com/wordpress/wpcontent/uploads/2012/12/ cinema-de-cozinha.pdf>. Acesso em: 04 mai. 2020.

LEITE, C.D.P. Imagens, experiência e acontecimento na infância e na educação. Linha Mestra, número 27. Campinas, p. 200-223, ago./set. 2015. Disponível em:

$<$ https://linhamestra27.files.wordpress.com/2016/02/27d cesar donizetti pereira leite imagens experiencia e acontecimento na infancia e na educacao.pdf $>$. Acesso em: 14 jul. 2020.

LEITE, C. D. P.; CHISTÉ, B. Imagens de crianças: travessias do universo infantil. Revista Educação, Porto Alegre, v. 38, n. 2, p. 272-279, maio-ago. 2015. Disponível em:

< https://revistaseletronicas.pucrs.br/ojs/index.php/faced/article/view/17764/13665>. Acesso em: 14 jul. 2020.

LEITE, C.D.P.; CHRISTOFOLETTI, R. Pra quê cinema? O que pode o cinema na educação e a educação no cinema? Fronteiras de encontros. In: FRESQUET, A. (Org.). Cinema e educação: a Lei 13.006 - reflexões, perspectivas e propostas. v. 1. Belo Horizonte: Universo Produção, 2015. p. 40-50.

MASSEY, D. Un sentido global del lugar. In: ALBET, A.; BENACH, N. (Org). Doreen Massey - un sentido global del lugar. Barcelona: Icaria Editorial, 2012.

Pelo espaço: uma nova política da espacialidade. Rio de Janeiro: Bertrand Brasil, 2008.

MIGLIORIN, C. Inevitavelmente cinema: educação, política e mafuá. Beco do Azougue: Rio de Janeiro, 2015.

. Por um cinema pós-industrial. Cinética, Rio de Janeiro, fev. 2011. Disponível em: < http://www.revistacinetica.com.br/cinemaposindustrial.htm $>$. Acesso em: 04 maio 2020.

OLIVEIRA JR, W. M. Outros espaços no cinema contemporâneo: campo de experimentações escolares? Quaestio: Revista de Estudos de Educação, v. 18, p. 67-85, 2016. Disponível em: 
$<$ http://periodicos.uniso.br/ojs/index.php/quaestio/article/view/2566>. Acesso em: 14 jul. 2020.

ORLANDI, L. B. L. Deleuze: entre caos e pensamento. In: AMORIM, A. C. R.;

GALLO, S.; OLIVEIRA JR, W. M. (Org). Conexões: Deleuze e Imagem e Pensamento e... Petrópolis: de Petrus e Alii Editora, 2011. 